REVIEW

\title{
SOME COMMONLY UNRECOGNIZED MANIFESTATIONS OF METABOLIC ARTHROPATHIES
}

\author{
MARK J. COBBY, MD AND WILLIAM MARTEL, MD
}

The metabolic arthropathies are characterized by the deposition of abnormal substances in or around joints. Certain features of some of these arthropathies and their significance have only recently been recognized and others have been insufficiently emphasized. An important group of conditions are the arthropathies related to renal failure and its treatment, namely, aluminum toxicity, periarticular calcification and crystal deposition, hyperparathyroidism, and dialysis-related amyloidosis. Crystal deposition diseases, specifically, gouty arthritis, calcium pyrophosphate deposition, and calcium hydroxyapatite deposition, are also reviewed.

KEY WORDS:

Metabolic; Arthropathies; Renal failure; Crystal deposition diseases

\section{INTRODUCTION}

The metabolic arthropathies are a heterogeneous group of disorders many of which result from deposition of abnormal substances in or around articular structures. This article reviews various manifestations of several metabolic arthropathies that are of current interest, or that have previously been insufficiently emphasized.

From the Department of Radiology, University of Michigan Medical Center, Ann Arbor, Michigan.

Address reprint requests to: William Martel, M.D., Department of Radiology, University of Michigan Hospitals, University Hospital B1G503/0030, 1500 East Medical Center Drive, Ann Arbor, MI 48109-0030.

Received April 1991.

(C) 1992 by Elsevier Science Publishing Co., Inc.

655 Avenue of the Americas, New York, NY 10010

$0899-7071 / 92 / \$ 5.00$

\section{ARTHROPATHIES RELATED TO RENAL FAILURE AND ITS TREATMENT}

In the last decade a new complication of long-term maintenance hemodialysis has emerged, termed dialysis-related arthropathy. The full extent of this severe and disabling joint disease is only just beginning to be realized. As yet it is uncertain whether this is a single entity with a spectrum of manifestations or an assortment of disorders. It is increasingly apparent however, that many of the manifestations are secondary to the intraosseous, articular, and periarticular accumulation of a previously unrecognized form of amyloid derived from circulating beta 2-microglobulin. This will be considered further, following a discussion of the more frequently recognized complications of chronic renal failure and its treatment.

Renal osteodystrophy encompasses a spectrum of pathological and radiological features resulting from a combination of secondary hyperparathyroidism, defective mineralization, and decreased bone formation. Its pathogenesis is complex, but includes excessive phosphate retention, resistance to the effect of parathyroid hormone, decreased synthesis of 1-25 vitamin $\mathrm{D}$ by the kidney and aluminum overload (1). The variable radiographic findings of osteomalacia, osteoporosis and osteosclerosis, are usually accompanied by soft tissue and vascular calcification $(2,3)$. Corrccting the metabolic abnormalities and deficiencies has resulted in a decrease in the incidence and severity of renal osteodystrophy, but this in turn has produced a number of unanticipated complications.

\section{Aluminum Toxicity}

Aluminum toxicity may result from the use of phosphate binding gels containing aluminum salts to 
lower the hyperphosphatemia or from dialysis solutions with a high aluminum content $(4,5)$. Two significant manifestations of this toxicity include acute myoclonic encephalopathy, characterized by episodes of abnormal speech, myoclonic jerks and convulsions (dialysis dementia), and vitamin D-resistant osteomalacia, associated with muscle weakness, a disproportionately severe anemia and normal serum alkaline phosphatase (fracturing dialysis osteodystrophy $(6,7,8)$.

Aluminum is toxic to osteoblasts and binds to osteoid, displacing calcium and inhibiting bone mineralization (9). The radiólogical features of this osteodystrophy include osteopenia and multiple fractures with wide radiolucent osteoid seams that heal poorly. These commonly involve the ribs (typically the second, third and fourth), vertebrae, hips, and pelvis $(10,11)$.

Aluminum also accumulates, and is concentrated in, articular structures, with the highest concentrations seen in the presence of amyloid deposition (12). As yet, it is uncertain whether it contributes to the onset of dialysis-associated arthropathy (13), but a synergistic action between aluminum and amyloid has been suggested (14).

The incidences of dialysis dementia and fracturing dialysis osteodystrophy have decreased significantly since the lowering of aluminum concentrations in dialysis solutions and the monitoring of plasma aluminum levels, although even modest aluminum overload can cause alterations of cerebral function (15).

\section{Periarticular Calcifications and Crystal Deposition}

Soft-tissue calcification occurs in renal failure when the plasma concentrations of calcium and phosphorus exceed their solubility product (16). In contrast, vascular calcification is unrelated to the calcium-phosphorus product, depending instead on the duration of dialysis (17). Periarticular deposits consist of hydroxyapatite crystals. They are frequently asymptomatic but can result in an aseptic tendonitis or periarthritis. The deposits may reach a considerable size, producing tumoral densities, often symmetrically distributed, about the large joints. These periarticular deposits may regress or progress during dialysis $(16,18)$. Capsular opacification can also occur and bone erosions beneath the periarticular deposits may be seen (19).

Intraarticular deposition of hydroxyapatite crystals has been described in the hand in patients who also have erosions of metacarpophalangeal and in- terphalangeal joints (20). In the spine, apatite crystals have been associated with a destructive spondyloarthropathy in long-term dialysis patients (21), but a causal relationship between the presence of the crystals and the spondyloarthropathy is equivocal. In subsequent series amyloid deposition has been implicated as the cause of the latter $(22,23)$.

Although chronic renal insufficiency results in hyperuricemia, tophaceous destructive arthritis due to secondary hyperuricemia is uncommon. When it does occur, the radiological appearances are identical to those of primary gout, but may involve unusual joints.

Oxalic acid is an end product of the metabolism of ascorbic acid and a number of aminoacids. Its accumulation in chronic renal failure managed by dialysis is probably the commonest cause of secondary oxalosis and can be aggravated by inappropriate and excessive vitamin $C$ supplementation $(24,25)$. Calcium oxalate crystals are deposited in the kidneys, heart, blood vessels, bone, synovium, articular cartilage and synovial fluid. Articular presentations include joint effusions, an acute symmetrical small joint arthritis and cutaneous calcinosis that may be mistaken for gouty tophi $(25,26)$. Radiographic manifestations are infrequent but distinctive (Figure 1) $(25,26)$. These principally involve the hands and feet. Miliary, moderately radioopaque densities, composed of calcium oxalate, occur predominantly. in the soft tissue of the digits, particularly around the pulps, in the synovium, periarticular structures and tendon sheaths, with a tendency to involve the flexor surfaces. Faint chondrocalcinosis and occasionally intraosseous calcifications may also be seen. Subarticular erosions, intraosseous cysts and digital acroosteolysis have been described but require careful differentiation from the effects of secondary hyperparathyroidism.

\section{Hyperparathyroidism}

All of the articular manifestations described in primary hyperparathyroidism are seen in patients with renal osteodystrophy, although chondrocalcinosis is relatively unusual in secondary hyperparathyroidism. Articular lesions result from bone resorption, crystal deposition, and tendon or ligamentous laxity or rupture. Brown tumors develop from localized areas of trabecular resorption with accumulation of fibrous tissue and giant cells. With adequate hemodialysis, the changes due to secondary hyperparathyroidism rarely progress and usually decrease in severity.

Subperiosteal resorption of bone, typically in- 


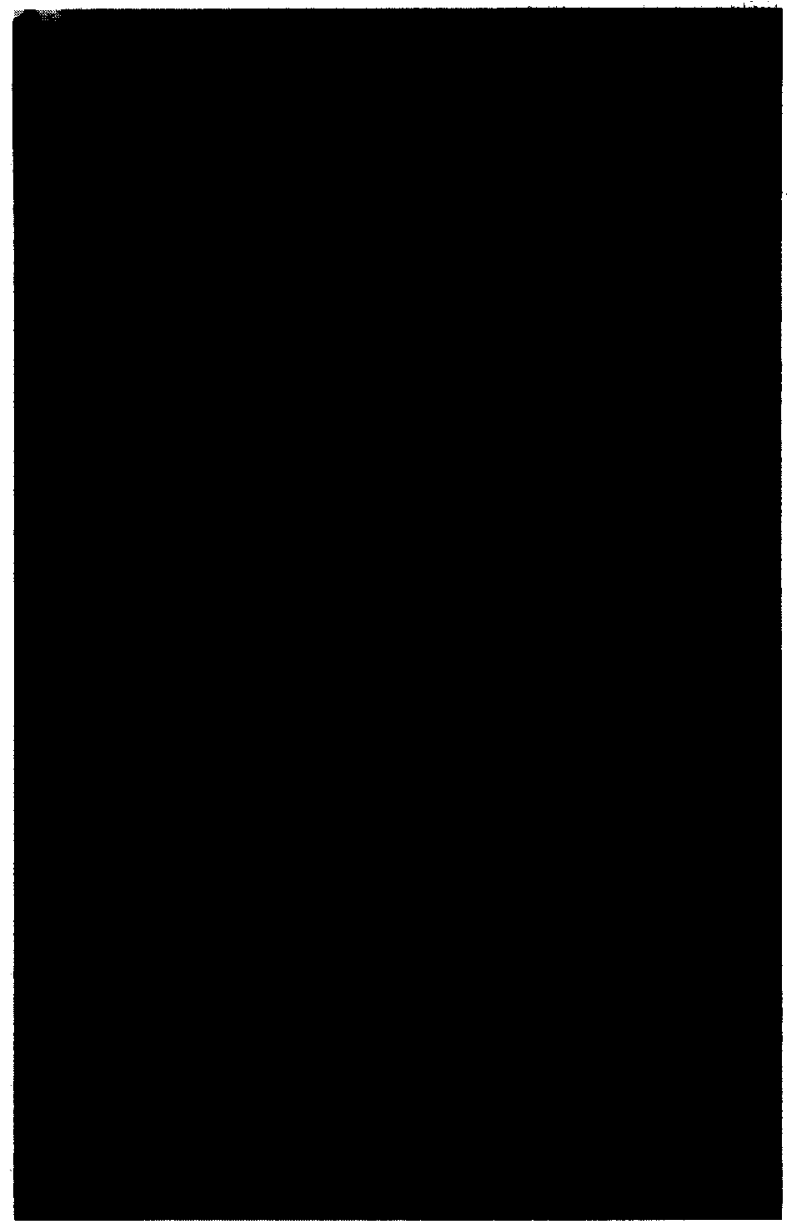

A

FIGURE 1. Secondary oxalosis in chronic renal failure. (A) A distinctive pattern of cutaneous, periarticular, and tendon-sheath calcification is shown. Acroosteolysis of the index and little fingers, together with subchondral erosions of the first carpometacarpal joint, are also observed. (B) Linear and milary calcification is shown in the soft tissues beneath the calcaneum in the same patent.

volving the radial aspect of the shaft of the phalanges, is a well-recognized feature of hyperparathyroidism. The marginal areas of joints may be involved, often in continuity with the shaft of the bone, resulting in periarticular erosions (Figure 2). These may be particularly prominent in the hands, wrists, and feet, and can mimic the appearances of an inflammatory arthritis $(27,28)$. The erosions may have well-marked or poorly defined, irrcgular outlines, and occur most frequently in the distal interphalangeal joints. When the metacarpophalangeal joints are involved, a predilection for the ulna aspect of the metacarpal head has been noted, contrasting with the radial predominance of rheumatoid arthritis (27). With control of the hyperparathyroidism the

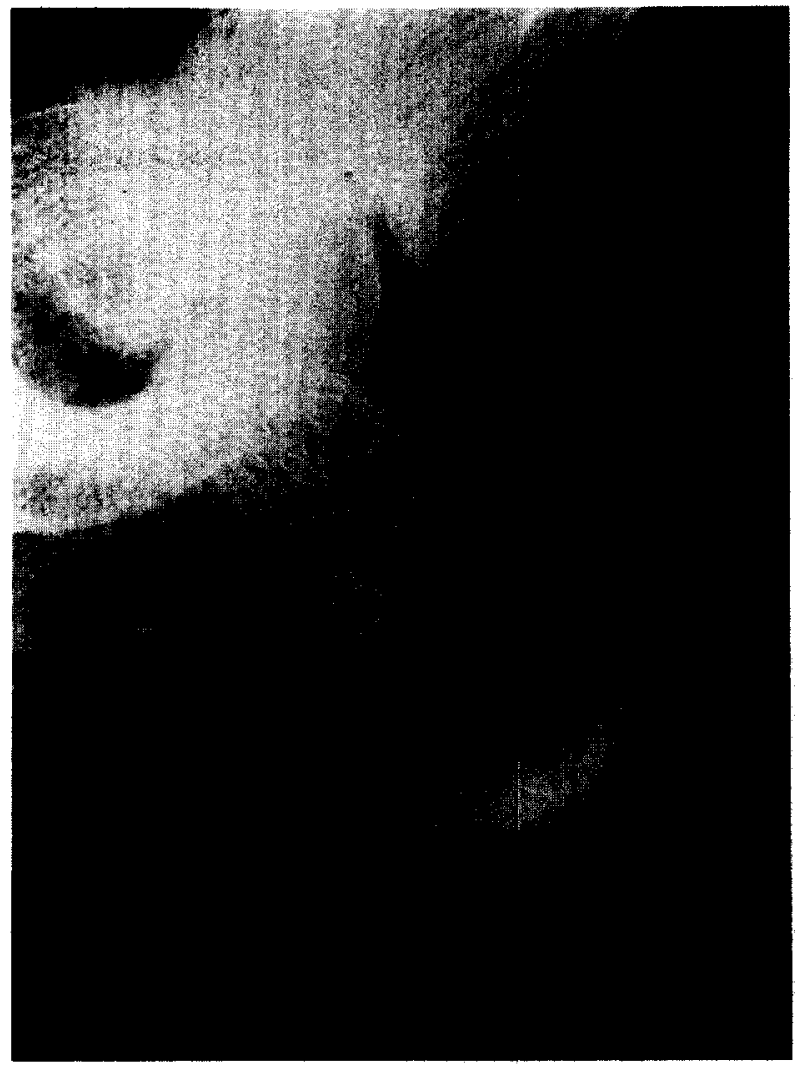

B

erosions become punched out, well-defined corticated areas of bone destruction. The joint spaces usually remain preserved.

Subchondral bone resorption occurs in the axial as well as the appendicular skeleton. It results in loss of definition of the subchondral bone and collapse of the articular surface. This may be accompanied by poorly defined intraosseous radiolucencies and subchondral sclerosis. The findings in the sacroiliac joints are most distinctive, where symmetrical, illdefined erosions with sclerotic articular margins predominantly involve the iliac sides of the joints. In the early stages the findings can be similar to those of ankylosing spondylitis (29). Subchondral bone resorption at the discovertebral junctions results in mulliple Schmorl's nodes, and may cause irregular destruction of the vertebral end plates. The thoracic spine is usually involved (29).

Although secondary hyperparathyroidism and crystal deposition may contribute to the osseous and articular findings observed in chronic renal failure and its treatment $(30,31,32)$, it is becoming increasingly apparent that some of the abnormalities previously attributed to these conditions are in fact due to 


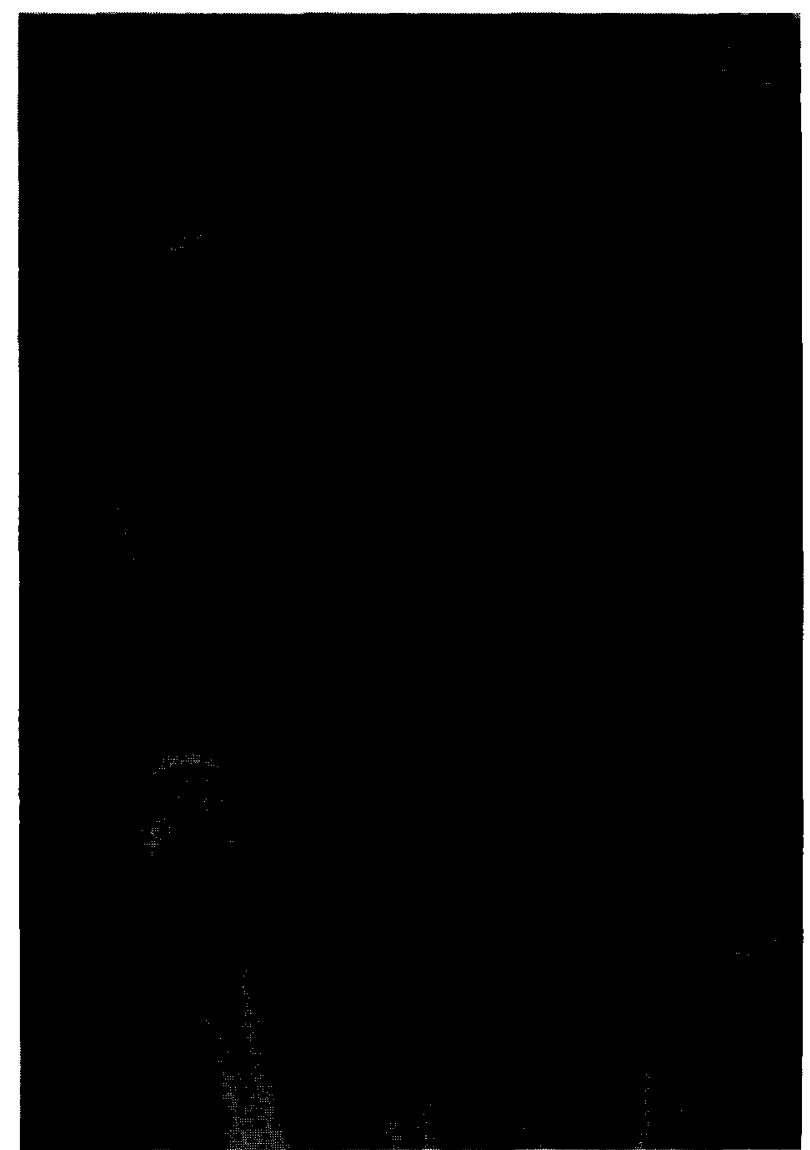

FIGURE 2. Secondary hyperparathyroidism with marginal erosions in the hand. Typical changes of secondary hyperparathyroidism duc to chronic renal failure are evident, including subperiosteal resorption and acroosteolysis. In addition, numerous marginal erosions are shown, most pronounced in the UIP joints and along the ulna aspects of the metacarpal heads (arrows).

dialysis-related amyloidosis. This is discussed in the following section.

\section{Dialysis-Related Amyloidosis}

A painful dialysis-related arthropathy, unrelated to crystal deposition or renal osteodystrophy, has recently been shown to be due to the deposition of a unique form of amyloid derived from circulating beta 2 -microglobulin $(33,34,35)$. It is characterized by painful stiff joints, usually first involving the shoulder, and less commonly the hands, wrists, knees, and other large joints (36). Involvement tends to be bilateral and symmetrical, and is frequently associated with the carpal tunnel syndrome and tenosynovitis $(36,37)$. The condition is seldom seen before five years of treatment but occurs with in- creasing frequency the longer the duration of dialysis. After ten years, up to $80 \%$ of patients may be symptomatic (37).

The amyloid protein is derived from circulating beta 2-microglobulin, a low-molecular-weight protein that is normally freely filtered and metabolized by the kidney (38). It is not, however, readily dialysed by the commonly used Cuprophane membranes. In long-term-maintenance hemodialysis this results in elevated serum levels with progressive accumulation and deposition in bony and soft-tissue structures. Even with the recently introduced higher permeability membranes that will dialyse beta $2-\mathrm{mi}$ croglobulin, its rate of formation still exceeds the rate of removal (39).

Although due to a distinctive biochemical form of amyloid, dialysis-related amyloidosis demonstrates many similar clinical and radiological findings to those seen in immunoglobulin associated amyloidosis $(40,41)$. As in immunoglobulin-related amyloidosis, the amyloid protein accumulates in all components of the joint and its surrounding tissues, with the radiological findings reflecting this intraarticular- and periarticular distribution. The findings are usually bilateral and symmetrical, with well-defined subarticular radiolucent lesions, typically in the wrists, hips, and shoulders, occurring in association with soft-tissue masses (Figure 3$)(34,42,43)$. In the large joints the appearances can mimic those of pigmented villonodular synovitis. Articular and intraosseous deposits may be asymptomatic (34).

In the wrist the radial aspect is most often involved, typically with $2-3 \mathrm{~mm}$ diameter radiolucencies initially being seen in the lunate, capitate, and scaphoid bones (Figure 3A) $(42,44)$. In the shoulder the lesions are usually found around the anatomical neck of the humerus. In the hip, the acetabular radiolucencies are immediately subarticular and often directly superior to the joint space. They characteristically develop in the subcapital region of the femur along the superolateral aspect of the neck where they are associated with a high incidence of pathological fracture (Figure 3B) $(34,42)$.

These focal radiolucent lesions slowly progress in size and typically develop fine sclerotic margins 2 to 4 years after they first appear (42). In the early stages, the surrounding trabeculae may show increased density, especially around the acetabular lesions. The radiolucent lesions occasionally appear multiloculated or coarse as they increase in size. Internal mineralization, bony expansion, and periosteal reactions do not occur. The joint space is preserved until late in the disease.

These lesions are probably the result of a combi- 


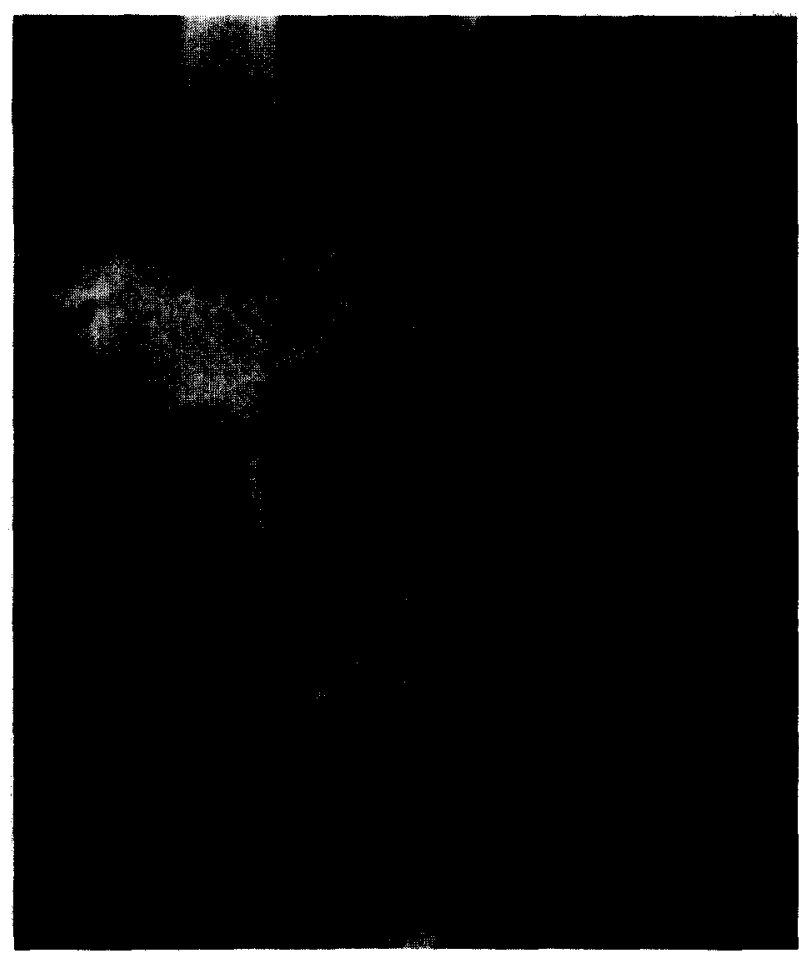

$\mathbf{A}$

nation of pressure scalloping from synovial masses and intraosseous subchondral deposits. Occasionally they remain static in size over a number of years, but they do not regress and show no relationship to other signs of renal osteodystrophy. These features help to distinguish them from brown tumors of hyperparathyroidism.

Occasionally, predominantly in the distal interphalangeal joints and unrelated to hyperparathyroidism or crystal deposition, severe subchondral erosions with marked osseous destruction are demonstrated resembling the appearances of erosive osteoarthritis (Figure 4) $(31,32)$. Corner erosions of vertebral bodies resulting in Schmorl's nodes may also occur (45). The cause of these abnormalities and their possible relationship to amyloidosis have not been determined.

Newer imaging techniques are useful for showing the extent, distribution, and location of involvement and to characterize the abnormalities. Computerized tomography of biopsy-proven amyloid lesions in the shoulder, femoral head, acetabulum, patella, and talus and has demonstrated well-defined, often multilocular, periarticular cystic lesions with internal attenuation values between 0 and 30 H.U. $(42,44)$. A soft-tissue component is not always identified (46).

Magnetic resonance (MR) imaging may demonstrate particularly well the extent and distribution of

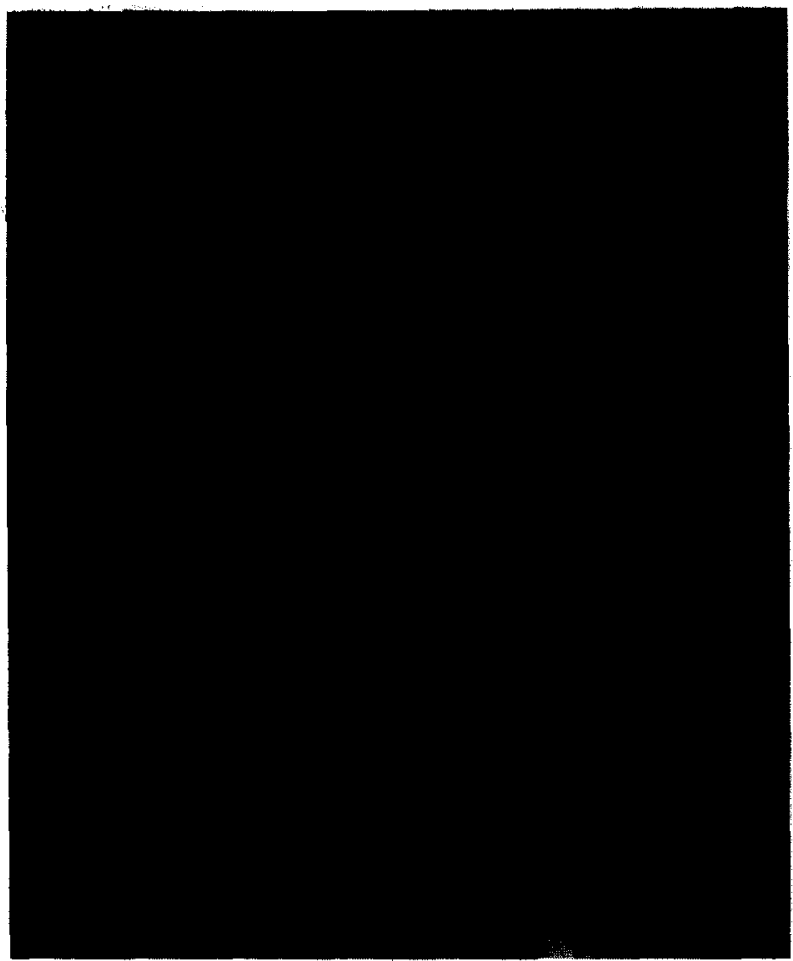

B

FIGURE 3. Dialysis related amyloidosis. (A) Wrist: Numerous radiolucent lesions are present in the scaphoid, lunate, capitate and hamate. The lunate has partially collapsed with widening of the scapholunate intraosseous distance. Erosions of the carpal bones, the proximal intermetacarpal joints, the distal radioulnar joint and the ulna notch are demonstrated (arrow). The joint spaces are preserved or slightly widened. (B) Left hip: A pathological fracture (white arrow) is shown through a large radiolucent lesion (black arrows) involving the superolateral aspect of the femoral neck. Further erosions are present in the subcapital region of the femur (open arrows) and the medial wall of the acetabulum.

osseous, articular, and soft-tissue involvement by amyloid (Figure 5). Lesions that are apparently intraosseous on conventional radiographs may be shown to be contiguous with well-defined articular surface erosions on MR imaging. The amyloid deposition has an intermediate-to-low signal intensity on all sequences. Synovial involvement may be associated with a significant joint effusion. The MR signal characteristics of amyloid infiltration, intermediate between fibrocartilage and muscle on all sequences, distinguish it from cellular or high water containing lesions, such as inflammatory masses, acute or chronic synovitis, and brown tumors of hyperparathyroidism. 


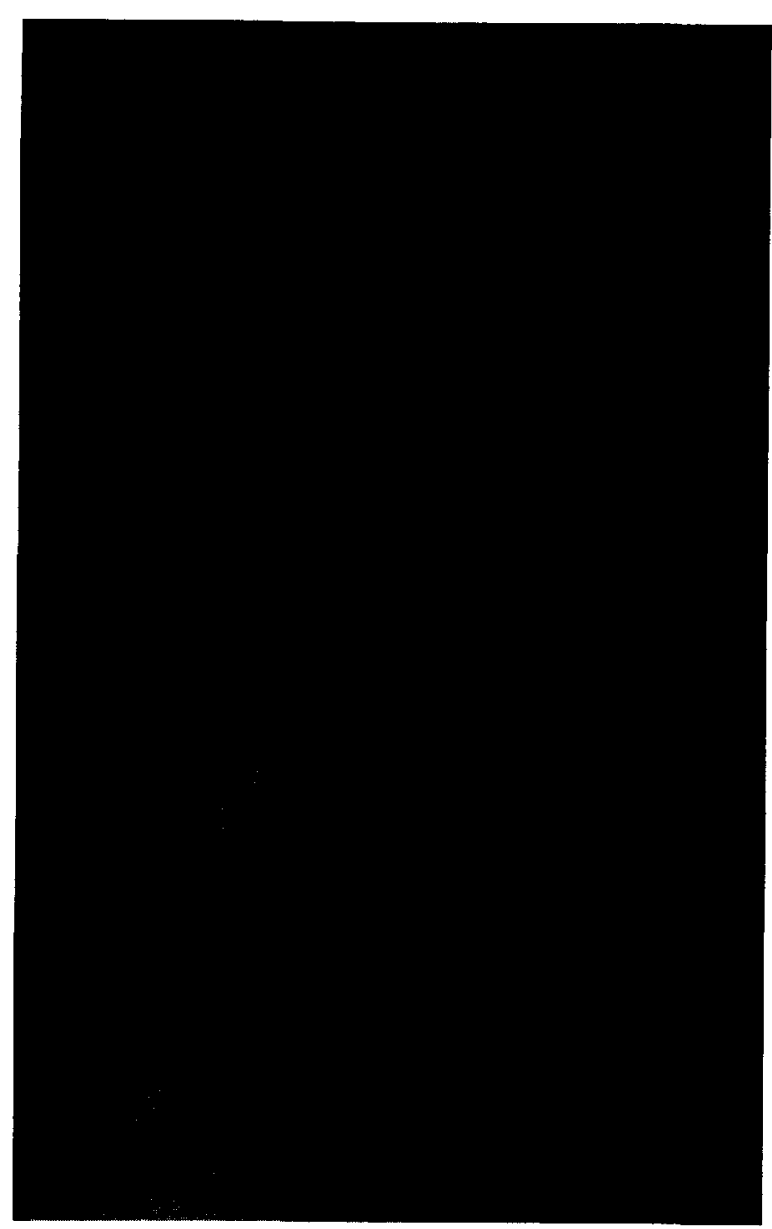

FIGURE 4. Unusual arthropathy in a 36-year-old man on long-term hemodialysis. Extensive subchondral erosions are shown involving the DIP joints of the index, middle, and ring fingers, the little finger PIP joint, and the first carpometacarpal joint. The appearance and distribution of the findings resemble erosive osteoarthritis. However, joint space narrowing and numerous marginal erosions are demonstrated in the carpal bones, the PIP joints and the MCP joints, particularly along the ulna aspect of the metacarpal heads (arrows). Similar findings were present in the right hand. There was no current evidence of secondary hyperparathyroidism. The cause of this occasionally observed arthropathy in long-term hemodialysis is uncertain.

Conventional radionuclide bone scanning is unreliable for identifying amyloid deposits, with some lesions showing increased radiotracer uptake while others demonstrate no abnormal uptake (47). Scintigraphic scanning with iodine-123 labeled serum amyloid P component has been assessed in systemic (nondialysis related) amyloidosis (48). The radioisotope appears to localize rapidly and specifically in amyloid deposits. As amyloid P component is common to all forms of amyloid (33), this isotope may prove to be a valuable noninvasive method of screening for dialysis-related amyloidosis, assessing the extent of involvement and monitoring its progress.

A rapidly progressive destructive spondyloarthropathy that simulates an infectious discitis has also been described in patients on long-term hemodialysis (Figure 6) $[21,22,23,45,49,50)$. Although this may involve any intervertebral level, the cervical spine is a particularly common site to be affected, contrasting with the intervertebral changes of hyperparathyroidism, which has a predilection for the thoracic spine. The presenting symptoms are of localized pain with radiographic changes occurring rapidly over a period of weeks to months. The char-

FIGURE 5. Magnetic resonance imaging in dialysis-related amyloidosis. Anterior (A \& B) and posterior (B \& C) coronal images of the knee. (A \& C) GE 1.5T; SE 2000/25. (B \& D) SE 2000/80. Numerous low signal intensity softtissue deposits, some arranged in a whorl-like pattern, are shown in the synovium (white arrows) and around the tibial origin of the posterior cruciate ligament (black arrow). The deposits have a low signal intensity on the first and second echo images, contrasting with the high signal intensity of the surrounding joint effusion on the second echo images. Tibial plateau erosions also contain material with a low signal intensity on both echoes (black arrow $\mathcal{E}$ open arrow). (E) Axial view (SE 600/25). The extent of the tibial plateau erosions (arrows) and surrounding abnormal soft tissues are well demonstrated.

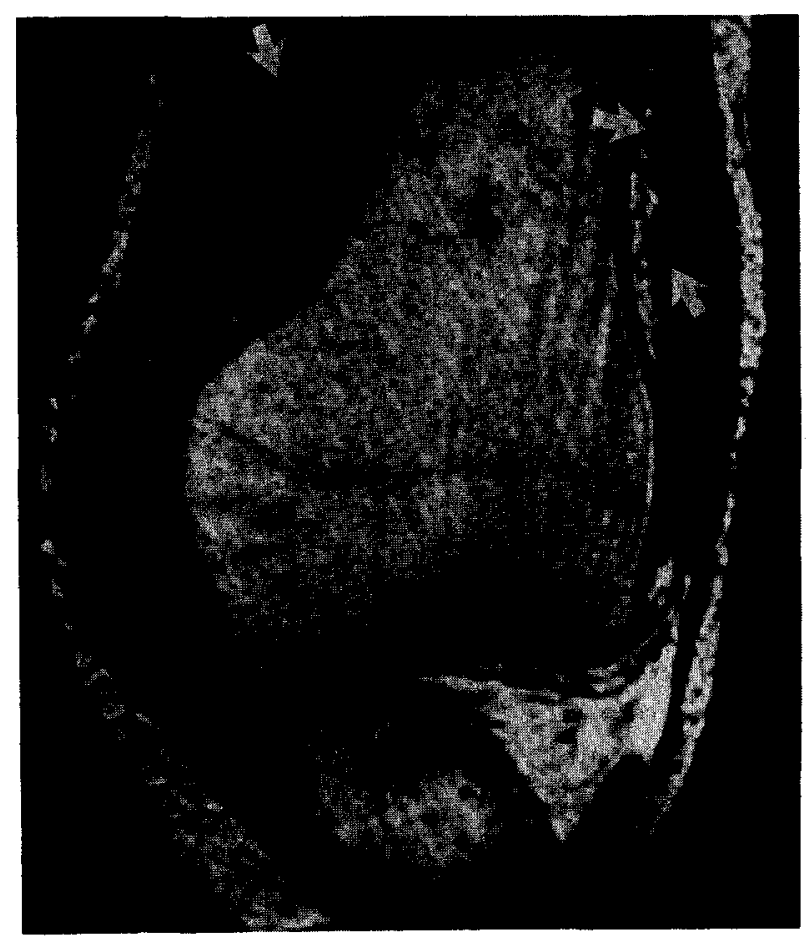

$\mathbf{A}$ 


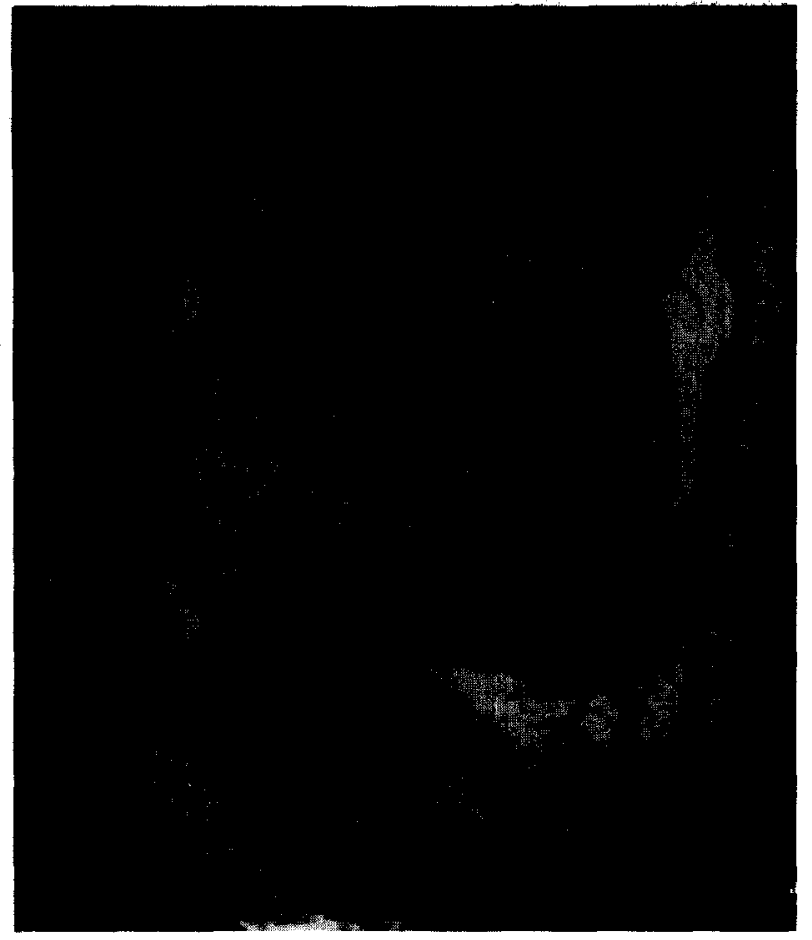

B

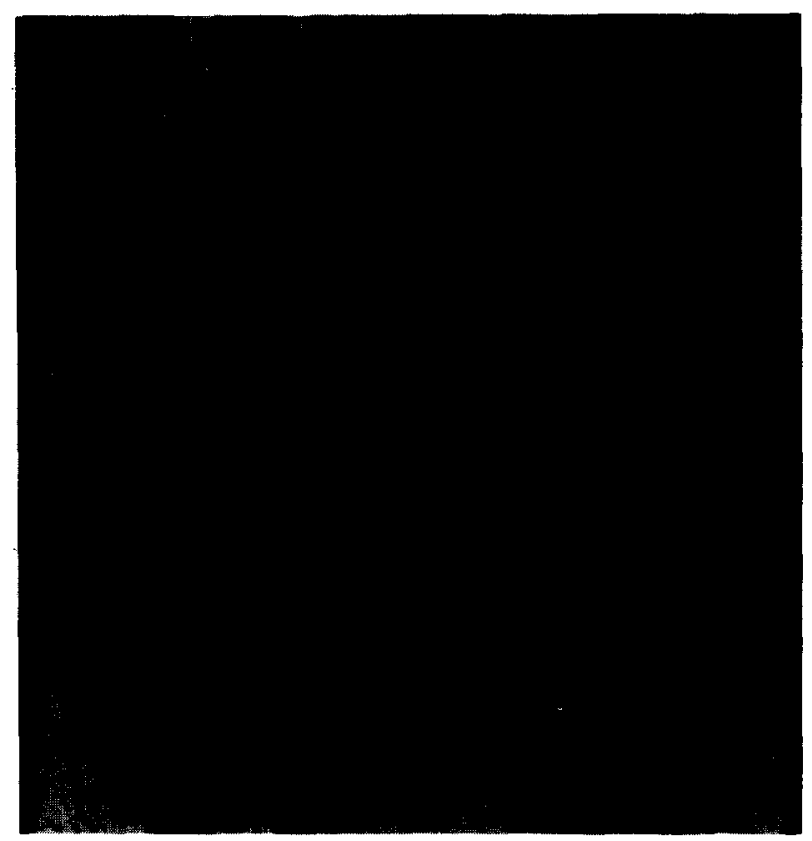

C

\section{FIGURE 5 continued.}

acteristic features include progressive disc space narrowing, marked ill-defined and extensive endplated erosions, and modest subchondral sclerosis, usually confined to one or two levels. A helpful differentiating feature from infection is the absence of an adjacent soft-tissue mass or swelling. Similar findings may also be seen in the facet joints $(22,23)$.
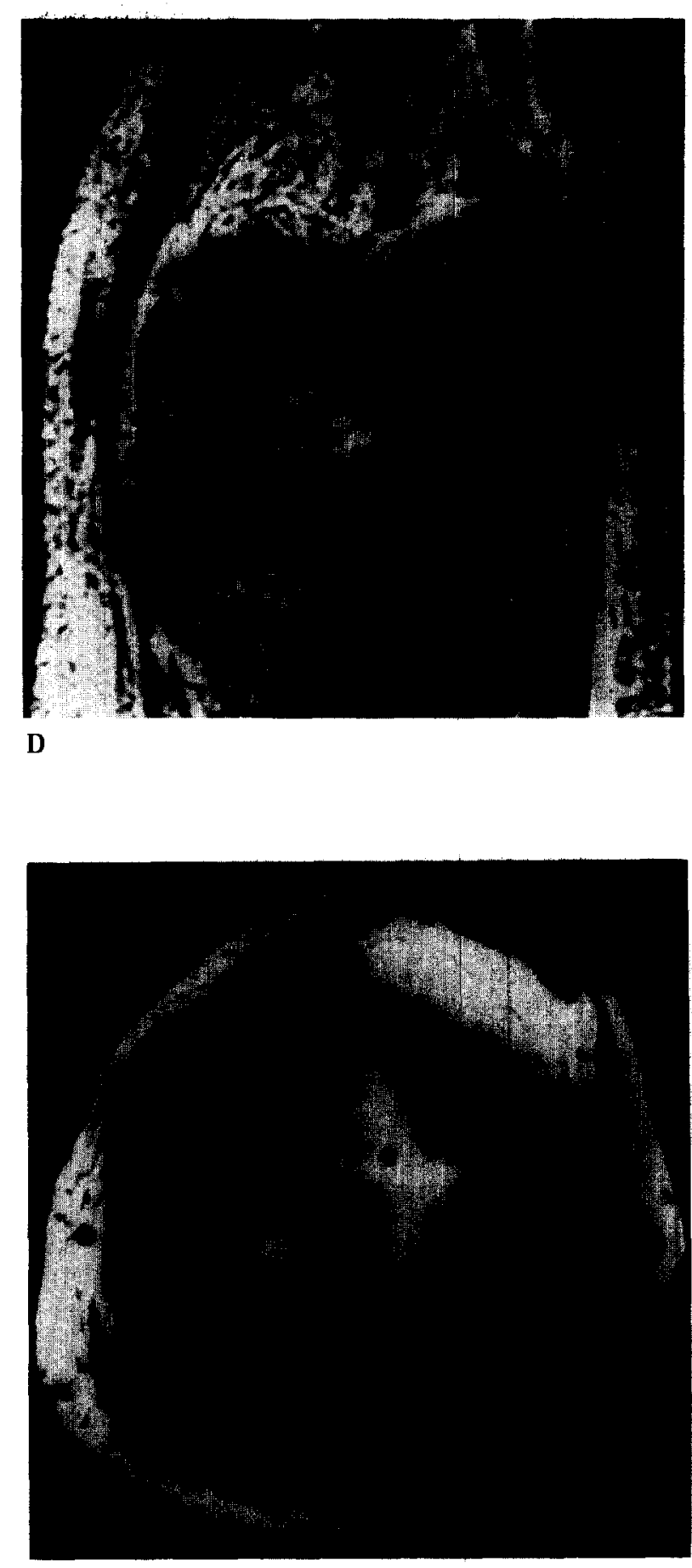

$\mathbf{E}$

Early studies in which calcium pyrophosphate and hydroxyapatite crystals were found in these lesions suggested this may be a crystal induced arthropathy $(21,49)$. More recently, beta 2-microglobulin-derived amyloid has been documented in the lesions, sometimes in association with characteristic amyloid changes in other joints $(22,23)$. It would 


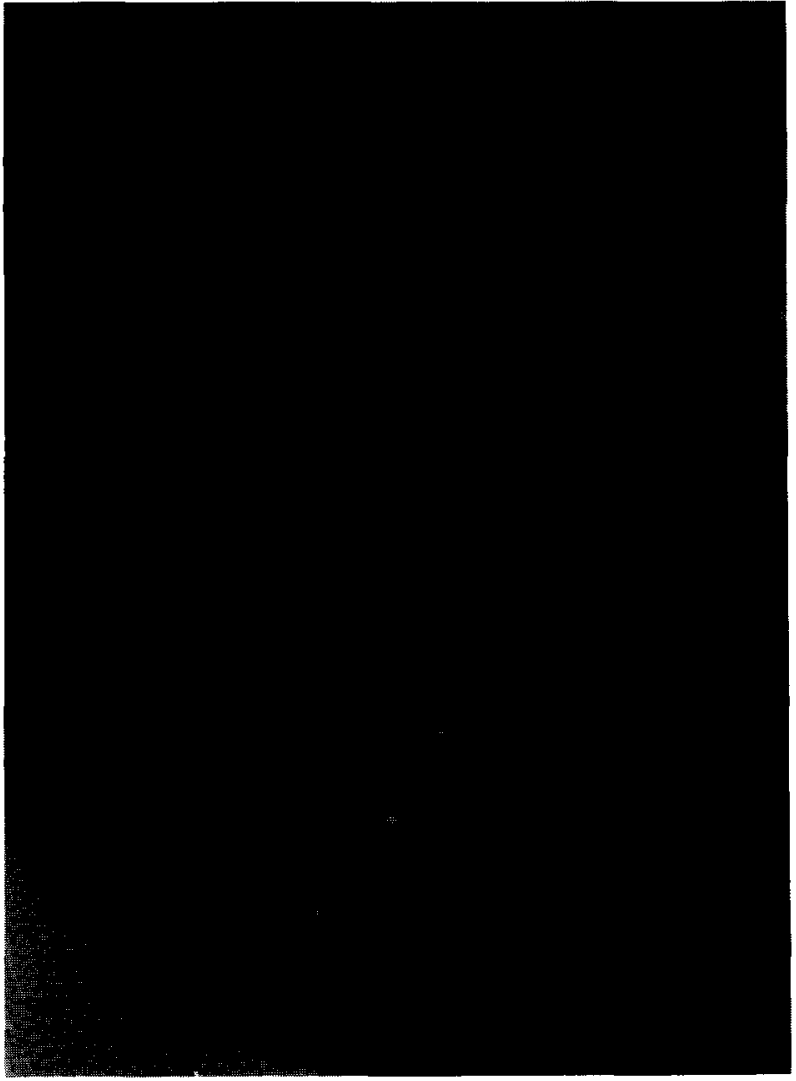

FIGURE 6. Cervical spine: Erosive spondyloarthropathy in long-term hemodialysis. Intervertebral disc space narrowing is shown at C5-C6 (open arrow) with erosion of the adjacent end plates, modest localised kyphosis, and slight forward slip of C5 on C6. The upper end-plated of C4 is also irregular.

appear therefore, that this is a further manifestation of dialysis-related amyloidosis and that the crystal deposition is most likely secondary to bone fragmentation and destruction rather than its cause.

MR imaging is valuable in distinguishing this destructive spondyloarthropathy from infectious spondylitis by demonstrating a low to intermediate signal intensity abnormality at the discovertebral junction on all sequences and the absence of a paraspinal or prevertebral mass (50). These changes contrast with infectious discitis where there is low signal intensity on T1-weighted images and irregular increased signal intensity from the disc and adjacent end plates on the T2-weighted images.

It is apparent that numerous and complex factors, not all of which are understood, contribute to the osseous and articular manifestations of patients with renal failure. Various complications arising from its treatment compound the difficulty of identifying a specific mechanism for many of the articular changes. Although amyloid deposition has recently been recognized as an important cause of osteoarticular damage in those on maintenance hemodialysis, it is likely that other factors and complex interactions will be identified as disease modifiers or significant pathogens in these patients.

\section{CRYSTAL-DEPOSITION DISEASES}

\section{Gouty Arthritis}

The pathogenesis and manifestations of gouty arthritis are the most well-defined and least controversial of the crystal-deposition diseases. Idiopathic gout accounts for the majority of cases, most frequently affecting men. It is conveniently divided into four stages: i) asymptomatic hyperuricemia, ii) acute gouty arthritis, iii) intercritical gout-an asymptomatic period between acute attacks that may last from months to years. Recovery between attacks is eventually incomplete and leads to iv) chronic tophaceous gout-occurs, usually after an interval of many years, in less than half of those who suffer from intermittent, episodic acute gouty attacks. It is typically an asymmetric polyarthritis with a tendency to involve the lower limbs.

Chronic tophaceous gout has a predilection for damaged synovial joints of the extremities, particularly the hands and feet, often occuring at the site of pre-existing osteoarthritis (51). Axial involvement is uncommon, but occurs occasionally in the acromioclavicular and sacroiliac joints. Chondrocalcinosis of fibrocartilage is sometimes associated. For unexplained reasons, the coexistence of gout and rheumatoid arthritis is very rare and similarly, superimposed septic arthritis of an involved joint is uncommon.

The radiological manifestations of chronic tophaceous gout reflect the pathological deposition of urate in all components of the joint and periarticular tissues. Eccentric soft-tissue nodules of modest increased amorphous density, which occasionally calcify, show an affinity for the dorsal and extensor surfaces of the hands, feet, ankles, elbows, and knees (Figure 7). The olecranon bursa is a frequent site. Bony and adjacent soft-tissue deposits result in eccentric subchondral, marginal and juxtaarticular erosions, usually with well-defined, "punched out" margins. Periosteal bone apposition is relatively uncommon, but may be seen adjacent to an obvious tophus with contiguous bone destruction. Bone mineralization is typically normal except in acute attacks, and the joint space is initially preserved. Subsequently, concentric joint space narrowing is observed $(52,53,54)$. 


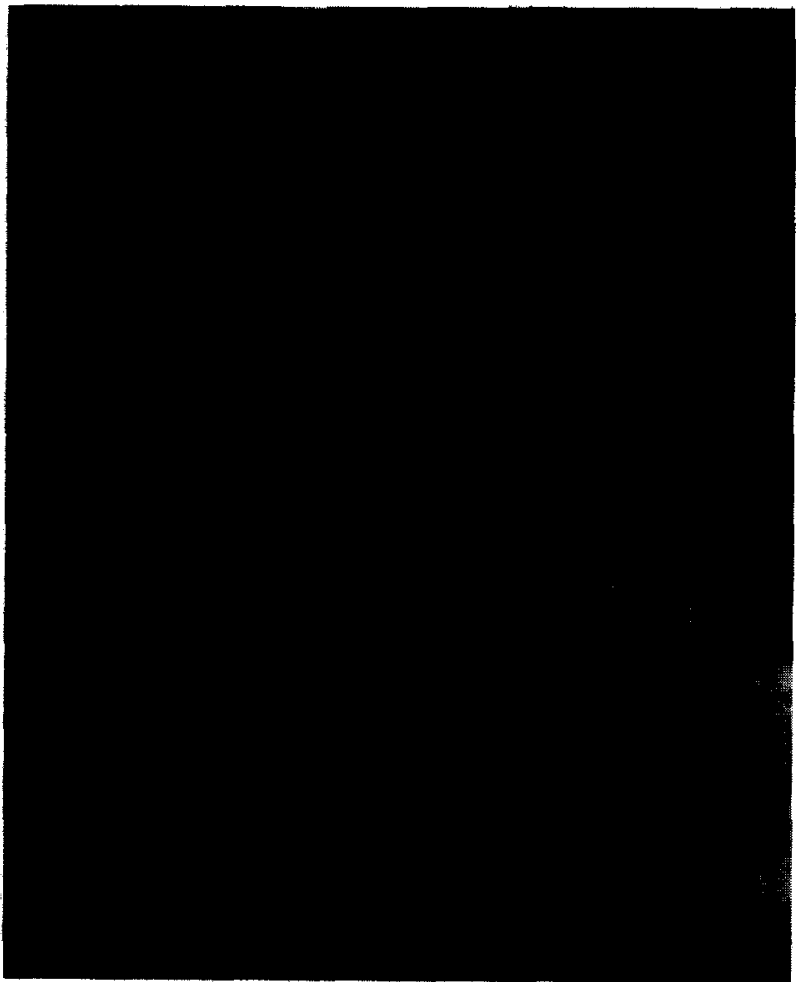

FIGURE 7. Gouty olecranon bursitis with erosion of the adjacent olecranon process. Characteristic amorphous areas of increased density are shown in the soft tissues behind the olecranon process. The underlying osseous erosion has overhanging margins (arrow); an uncommon finding outside of the hands and feet. A large effusion is present.

Bony ankylosis is very uncommon, but is occasionally observed in the carpus with extensive disease, and exceptionally in an interphalangeal joint. Intraosseous lesions occur near a joint, and are often multioculated with scalloped margins. Occasionally a solitary round area of bone destruction is seen. In the hands, wrists, and feet intraosseous lesions occasionally calcify (Figure 8) and may resemble enchondromas or bone infarcts (55). This is usually associated with extensive articular destruction and coexistent areas of soft-tissue calcification, frequently in the presence of renal impairment.

Osteoarthritis of the first metatarsophalangeal joint predisposes to this characteristic site of gouty tophaceous involvement (56). Erosions typically occur on the dorsal and medial aspect of the metatarsal head (Figure 9). The characteristic erosion with an overhanging elevated margin is seen principally in the hands and feet, and occurs in approximately $40 \%$ of those with erosions (54). Occasionally it may be observed at other articular sites (Figure 7).

\section{Calcium Pyrophosphate Deposition}

Articular deposition of calcium pyrophosphate (CPPD) is a common age-related phenomenon. It is frequently asymptomatic and unassociated with structural joint damage $(57,58)$. Occasionally, acute attacks of synovitis occur resulting in pseudogout (59). Attacks are often provoked by intercurrent illness, local trauma, or surgery and most commonly involve the knee, and less often the wrist, hip, shoulder, and elbow. Osteoarthritis and CPPD frequently coexist, but in some patients, a distinctive modified pattern of osteoarthritis is seen-." "pyrophosphate arthropathy" $(58,60,61)$. Characteristic features of this arthropathy, distinguishing it from conventional osteoarthritis, include an unusual articular and intraarticular distribution, large and numerous subchondral cysts, and often prominent osteophyte formation. The subchondral cysts have sclerotic indistinct edges and characteristically occur in clusters or as multiple small contiguous lucencies along the subchondral bone (Figure 10). Their presence may precede articular cartilage loss. Numerous intraarticular osteochondral fragments are frequently present. When profuse, these can occasionally be confused with synovial chondromatosis (62). Uncommonly, severe destructive changes may mimic ischemic necrosis or neuropathic joint disease.

Pyrophosphate arthropathy may occur secondary to a number of other metabolic conditions, including primary and secondary hemochromatosis (63). Familial forms of articular chondrocalcinosis have also

FIGURE 8. Intraosseous tophaceous calcification in gout. Prominent soft-tissue swelling with gouty erosions and osteophyte formation of both great toe metatarsophalangeal joints. In the right proximal phalanx, punctate and curvilinear calcification (black arrow) of an intraosseous tophaceous depusit is associated with extensive extraarticular bony destruction and an overhanging margin (white arrow).

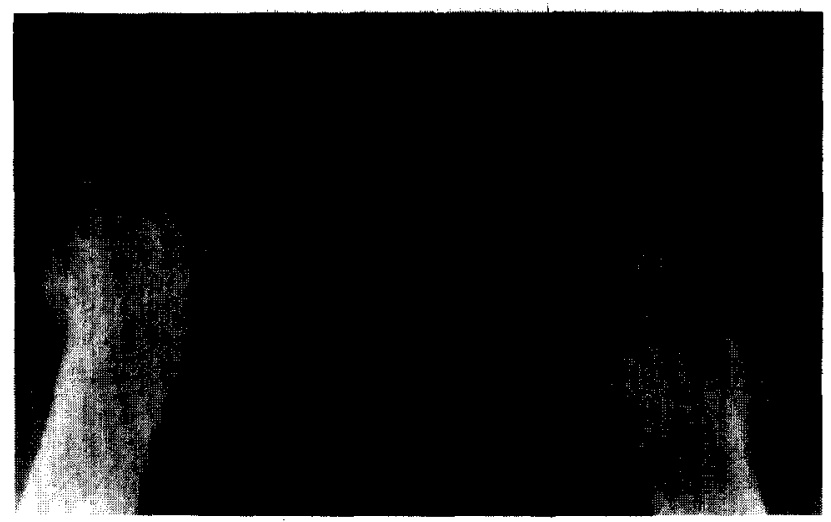




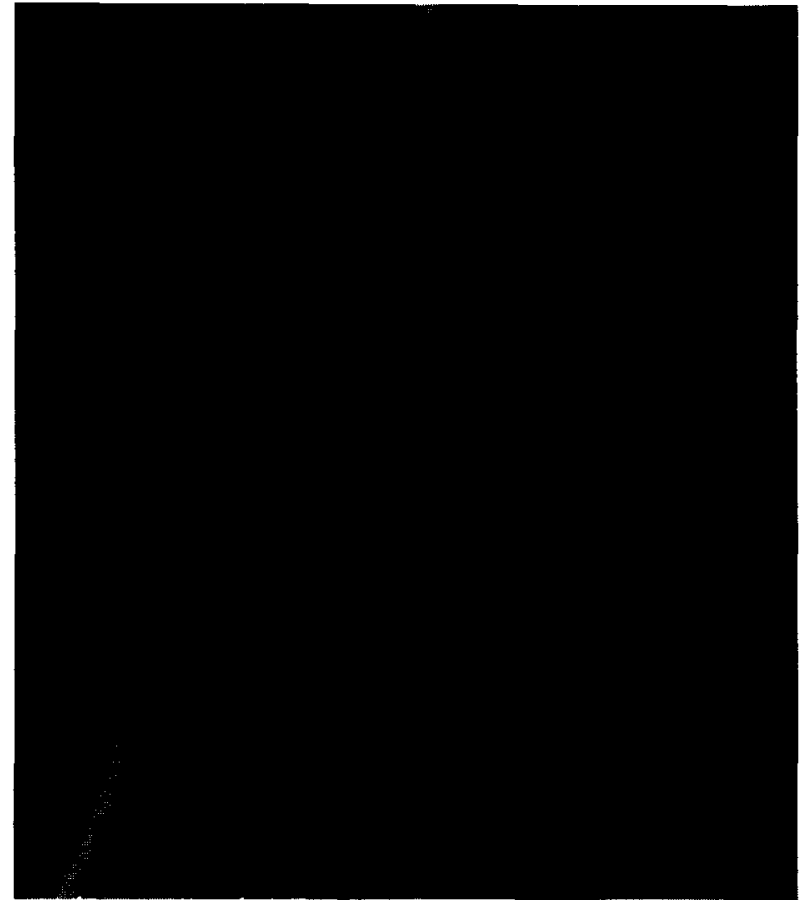

A

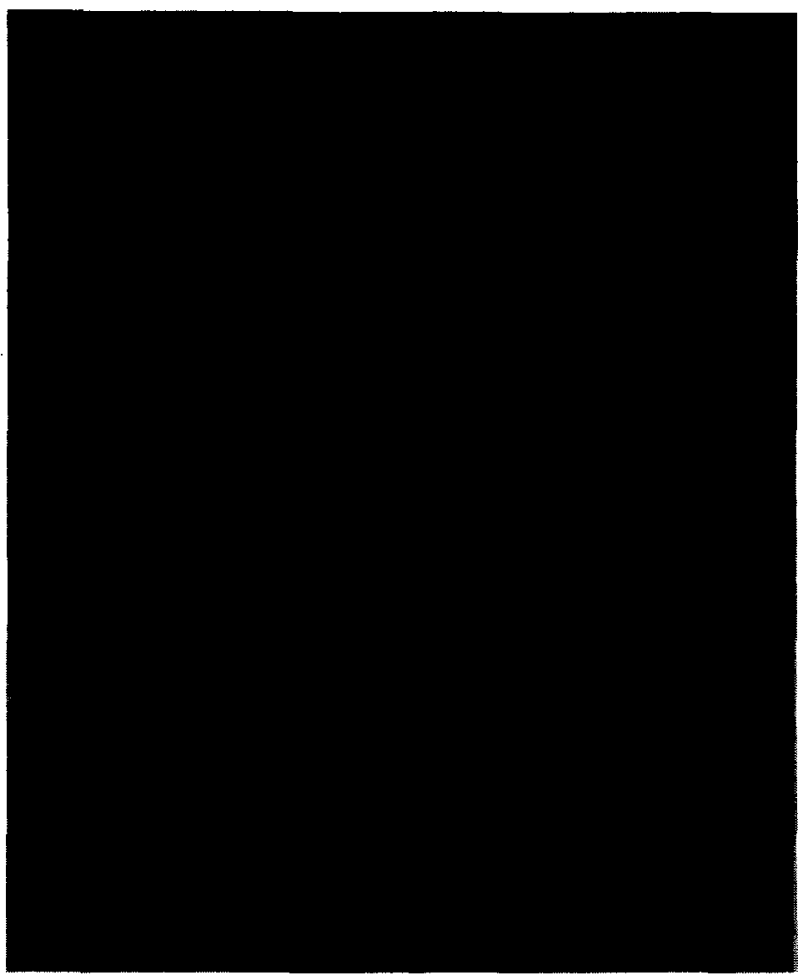

B

FIGURE 9. Bilateral great toe metatarsophalangeal (MTP) joint involvement in gout. (A) Anteroposterior view. (B) Medial oblique projection. Soft-tissue swelling is shown adjacent to the medial aspects of both MTP joints. Erosions are most evident on the oblique projection due to their dorsomedial location (arrows). The right MTP joint is a little narrowed.

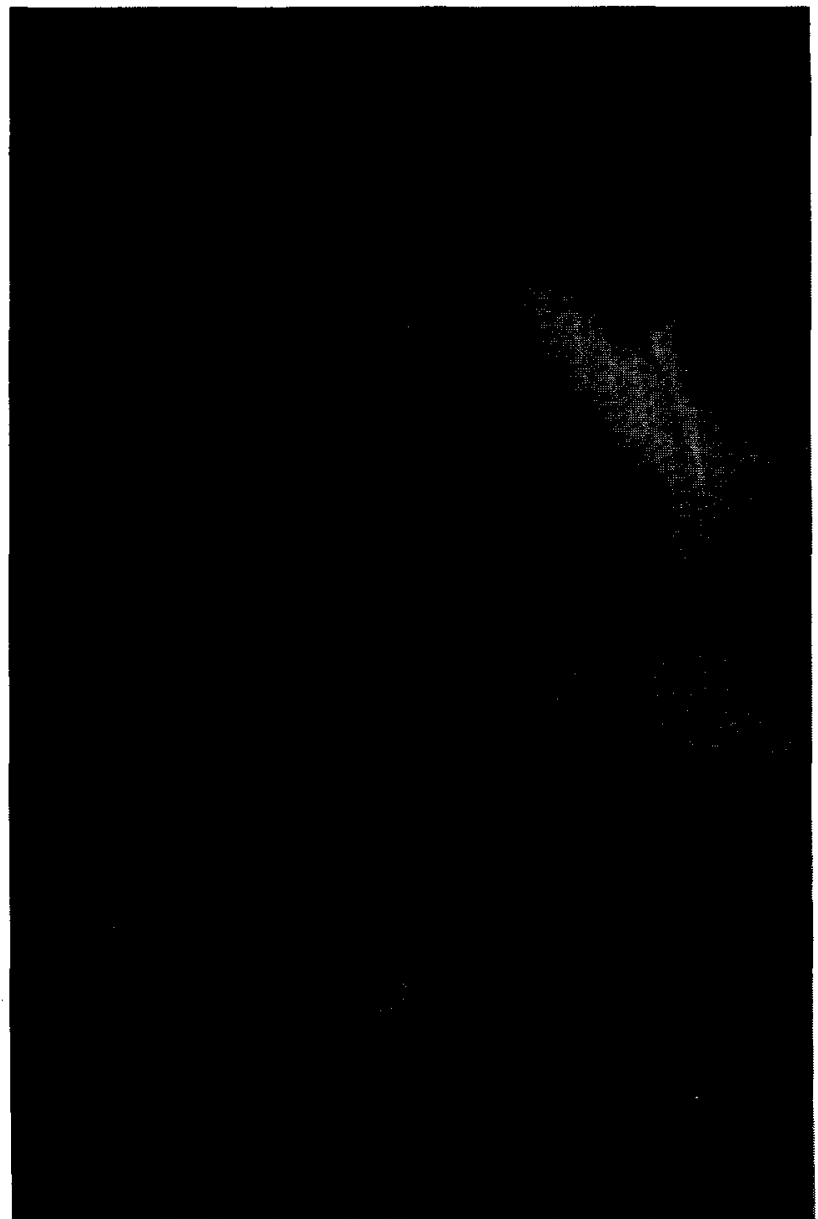

FIGURE 10. Pyrophosphate arthropathy of the right shoulder. Marked joint space narrowing, subchondral sclerosis, and prominent inferior osteophyte formation are shown, together with a number of intraarticular osteochondral fragments (arrow head) and narrowing of the rotator cuff. Multiple small subchondral radiolucencies parallel the articular surface of the humeral head (small arrows).

been described, often unassociated with articular symptoms or structural joint damage $(64,65)$.

The distinctive structural changes of pyrophosphate arthropathy occasionally precede radiologically identifiable cartilage calcification and should be considered whenever an unusual combination of articular changes are seen in osteoarthritis, such as the radiocarpal and metacarpophalangeal joint involvement $(58,60)$. Wrist involvement may be associated with carpal instability secondary to ligamentous laxity and disruption of the interosseous ligaments, especially between the scaphoid and lunate (66).

CPPD has a predilection for the fibrocartilagenous menisci of the knee, the triangular cartilage of the 
wrist, the public symphysis and the labra of the acetabulum and glenoid. It is more common than hyaline cartilage calcification, which occurs especially in the knee, wrist, hip, and elbow.

Hyaline cartilage calcification is not generally seen in the absence of fibrocartilage involvement (61). Surprisingly, in view of the fibrocartilagenous composition of the temporomandibular joint, involvement of this site is infrequent, although possibly underrecognized (67).

The characteristic appearance of fibrocartilage deposition is a coarse granular calification, whereas hyaline cartilage deposition has a more delicate linear appearance. A spectrum of changes are seen with minimal involvement affecting only the knee menisci, while in more severe deposition the synovium, capsule, ligaments, and bursae are involved. When tendons are affected, often long segments are involved (61). Crystal deposits in the menisci of the knee have also been observed to be transient on serial radiographs (68).

Massive tumoral deposition of calcium pyrophosphate in periarticular locations is a rare manifestation. These deposits may initially be mistaken for a malignant chondroid or other soft-tissue tumors and may be unassociated with other manifestations of CPPD disease; sites that have been cited include the temporomandibular joint $(69,70)$, wrist, and hands $(71,72,73)$.

\section{Calcium Hydroxyapatite Deposition}

Hydroxyapatite deposition is a well-recognized cause of various periarthritic inflammatory conditions (74). Macroscopic aggregates may be confirmed radiographically by the presence of localized areas of soft-tissue calcification. These deposits are commonly seen about the shoulder and small joints of the hands, although they are not necessarily symptomatic. Intraarticular deposition of hydroxyapatite crystals is less frequently observed but the accumulation of large quantities of crystals is associated with a striking form of destructive joint disease (Figure 11). It has been suggested, but not conclusively shown, that this may be a specific subset of osteoarthritis analogous to pyrophosphate arthropathy (75). The possibility of such an "apatite-associated-destructive-arthritis" has received little attention in the radiological literature.

Patients affected by this uncommon condition are usually elderly women who present with rapidly progressive joint damage, large, often blood-stained effusions, and joint instability. Shoulder joint involvement predominates, but lateral compartment

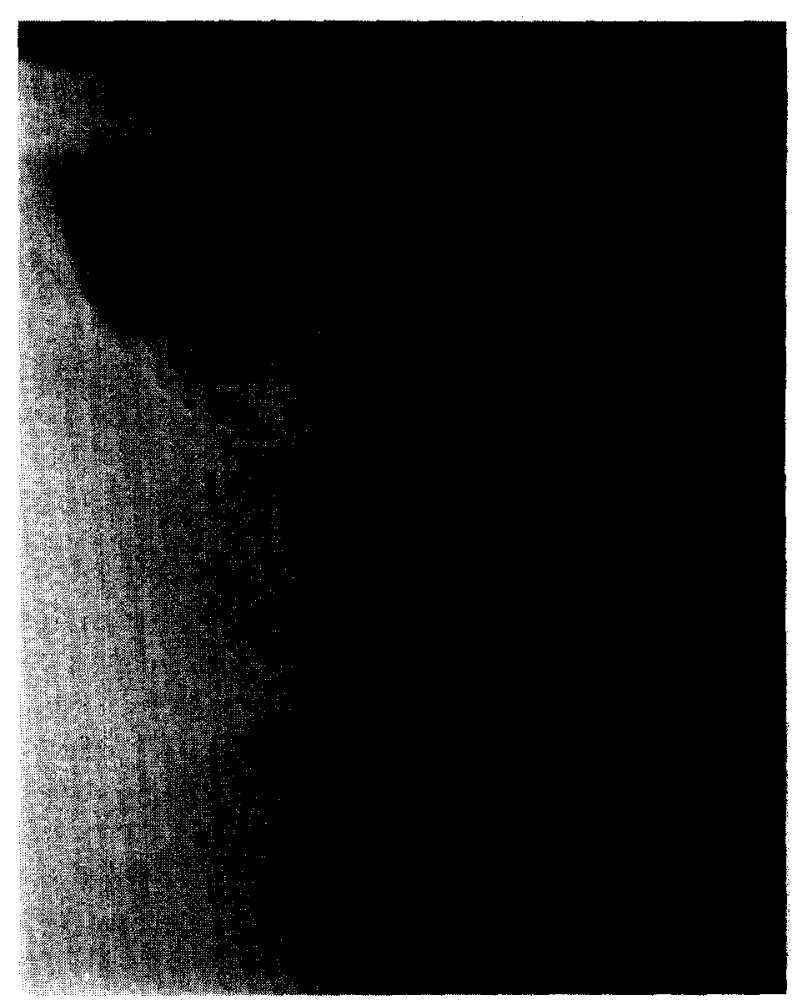

FIGURE 11. Apatite-associated arthropathy. Marked subchondral hony attrition of the humerus, glenoid, acromium, and outer portion of the clavicle is shown with little subchondral sclerosis and no osteophyte formation. A number of bony fragments are evident (white arrow). Disruption of the rotator cuff has resulted in upward subluxation of the humeral head. A smooth pressure defect along the medical aspect of the proximal humerus is present (black arrows). Numerous hydroxyapatite particles were aspirated from the shoulder of this elderly women with a large joint effusion. (Courtesy of I. Watt, M.D., Bristol, UK).

knee disease is common and the hip may also be affected $(76,77,78,79)$. Involvement of the midtarsal joints have also been described (77).

Radiographs demonstrate marked subchondral bony attrition, with relatively modest subchondral sclerosis in the absence, or presence of only minimal, osteophyte formation and large-joint effusions. Periarticular calcification is frequently present. Scalloping pressure defects of adjacent osseous structures occur from the large effusions. Periarticular osteoporosis is usually minimal or absent. Marginal erosions do not occur. Chondrocalcinosis may be present at remote joints. The appearances may mimic an atrophic form of neuropathic joint destruction, or overlap with some features of other diseases, such as rheumatoid arthritis or calcium pyrophosphate deposition disease $(76,77,78)$. 
It has been suggested that a number of named syndromes applied to this destructive arthropathy, such as Milwaukee shoulder (76), analgesic hip $(78,80)$, and rapidly progressive, or atrophic osteoarthritis, may represent a common articular response at different joint sites to a process possibly activated by apatite crystals (78). As with pyrophosphate arthropathy, it is important to avoid the implication that the crystals are necessarily the cause of the structural changes (77). In vitro and synovial fluid studies have shown that apatite crystals can induce activation of collagenase and other enzymatic pathways that may accelerate joint damage (76). The identification of hydroxyapatite crystals, however, requires special staining techniques with Alizarin red (81) or analytical electron microscopy (82). For this reason hydroxyapatite crystals and other basic calcium phosphates are easily overlooked in the routine analysis of synovium and synovial fluid. Many of the cases of a destructive arthropathy attributed to pyrophosphate disease originally described by Menkes and other authors, show the typical clinical and radiological features of apatite associated destructive arthropathy (83).

The complex interactions involved in the spectrum of disease manifestations exhibited in the crystal arthropathies, ranging from asymptomatic deposition, to acute synovitis and chronic structural joint damage are not completely understood. Pure crystal deposits are not always present. An association exists between gout and calcium pyrophosphate deposition, and between calcium pyrophosphate and hydroxyapatite deposition $(61,81)$. Mixtures of various basic calcium phosphates also occur (84). Whether the crystal deposition initiates the joint damage is questionable. It is possible that joint damage predisposes to crystal deposition, which in turn may modify the underlying disease process (85). Occasionally this results in a distinctive pattern of radiographic changes. The recognition of these are important in suggesting the diagnosis of a crystal-associated arthropathy and in identifying subsets of osteoarthritis that may have prognostic and therapeutic implications.

\section{REFERENCES}

1. Malluche H, Faugere M-C. Renal bone disease 1990: An unmet challenge for the nephrologist. Kidney Int 1990;38:193211.

2. Weller M, Edeiken J, Hodes PJ. Renal osteodystrophy. Am J Roentgenol 1968;104:354-363.

3. Greenfield GB. Roentgen appearance of bone and soft tissue changes in chronic renal disease. Am J Roentgenol 1972;116: 749-757.
4. Elliott HL, Dryburgh F, Fell GS, Sabet S, MacDougall AL. Aluminum toxicity during regular haemodialysis. Br Med J 1978;i:1101-1103.

5. McDermott JR, Smith AI, Ward MK, Parkinson IS, Kerr DNS Brain aluminum concentration in dialysis encephalopathy Lancet 1978;i:901-904.

6. Ward MK, Feest TG, Ellis HA, et al. Osteomalacic dialysis osteodystrophy: Evidence for a water-borne aetiulogical agent, probably aluminum. Lancet 1978;i:84i -845 .

7. Pierides AM, Edwards WG, Cullum UX, McCall JT, Ellis HA. Hemodialysis encephalopathy with osteomalacic fractures and muscle weakness. Kidney Int 1980;18:115-124.

8. Parkinson IS, Ward MK, Feest TG, Fawcett RWP, Kerr DNS. Fracturing dialysis osteodystrophy and dialysis encephalopathy. Lancet 1979;i:406-409.

9. Dunstan CR, Evans RA, Hills E, Wong SYP, Alfrey AC. Effect of aluminium and parathyroid hormone on osteoblasts and bone mineralization in chronic renal failure. Calcif Tissue Int 1984;36:133-138.

10. Garrett P, Mcwade M, O'Callaghan J. Radiological assessment of aluminium-related bone disease. Clin Radiol 1986;37:6370.

11. Kriegshauser JS, Swee RG, McCarthy JT, Hauser MF, Aluminium toxicity in patients undergoing dialysis: Radiographic findings and prediction of bone biopsy results. Radiol 1987; 164:399-403.

12. Netter $\mathbf{P}$, Kessler M, Gaucher A, et al. Aluminium and dialysis arthropathy. Lancet 1988;i:886-887.

13. Netter P, Kessler M, Gaucher A, Bannwarth B. Does aluminum have a pathogenic role in dialysis associated arthropathy. Ann Rheum Dis 1990;49:573-575.

14. Yver L, Blanchier D, Buiquang D, Cabanne JF, Charmes JP, Meftahi J. Does aluminium induce dialysis amyloidosis? Nephrol Dial Transplant 1987;2:450-451.

15. Altmann P, Dhanesha U, Hamon C, Cunningham J, Blair J, Marsh F. Disturbances of cerebral function of aluminium in haemodialysis patients without overt aluminium toxicily. Lancet 1989;ii:7-11.

16. Parfitt AM. Soft-tissue calcification in uraemia. Arch Intern Med 1969:124:544-556.

17. Ritz E, Krempien B, Mehls O, Malluche HH. Skeletal abnormalities in chronic renal insufficiency before and during maintenance hemodialysis. Kidney Int 1973;4:116-127.

18. Meema HE, Oreopoulos DG. Morphology, progression, and regression of arterial and periarterial calcifications in patients with end-stage renal disease. Radiol 1986;158:671-677.

19. Meneghello A, Bertoli M, Romagnoli GF. Unusual complication of soft tissue calcifications in chronic renal disease: The articular erosions. Skeletal Radiol 1980;5:251-252.

20. Schumacher HR, Miller JL, Ludivico C, Jessar RA. Erosive arthritis associated with apatite crystal deposition. Arthritis Rheum 1981;24:31-37.

21. Kaplan P, Resnick D, Murphey M, et al. Destructive noninfectious spondyloarthropathy in hemodialysis patients: A report of four cases. Radiol 1987;162:241-244.

22. Naidich JB, Mossey RT, McHeffey-Atkinson B, et al. Spondyloarthropathy from long-term hemodialysis. Radiol 1988;167: 761-764.

23. Orzincolo C, Bedani PL, Scutellari PN, Cardona P, Trotta F, Gilli $P$. Destructive spondyloarthropathy and radiographic follow-up in hemodialysis patients. Skeletal Radiol 1990;19: 483-487.

24. Pru C, Eaton JR, Kjellstraud C. Vitamin C intoxication and hyperoxalemia in chronic hemodialysis patients. Nephron 1985;39:112-116. 
25. Hoffman GS, Schumacker HR, Paul $\mathrm{H}$ et al. Calcium oxalate microcrystalline-associated arthritis in end-stage renal disease. Ann Intern Med 1982;97:36-42.

26. Reginato AJ, Seoane JLF, Alvarez CB, et al. Arthropathy and cutaneous calcinosis in hemodialysis oxalosis. Arthritis Rheum 1986;29:1387-1396.

27. Resnick DL. Erosive arthritis of the hand and wrist in hyperparathyruidism. Radiology 1974;110:263-269.

28. Hamilton S, Knickerbocker WJ. Peri-articular erosions in the hands and wrists in haemodialysis patients. Clin Radiol 1982, 33:19-24

29. Resnick D, Niwayama G. Subchondral resorption of bone in renal osteodystrophy. Radiology 1976;118:315-321.

30. Rubin LA, Fam AG, Rubenstein J, Campbell J, Saiphoo C. Erosive azotemic osteoarthropathy. Arthritis Rheum 1984;27: $1086-1094$

31. Naidich JB, Karmel MI, Mossey RT, Bluestone PA, Stein HL. Osteoarthropathy of the hand and wrist in patients undergoing long-term hemodialysis. Radiology 1987;164:205-209.

32. Goldstein S, Winston E, Chung TJ. Chopra S, Pariser K Chronic arthropathy in long-term hemodialysis. Am J Med 1985;78:82-86

33. McClure J, Bartley CJ, Ackrill P. Carpal tunnel syndrome caused by amyloid containing B2 microglobulin: a new amyloid and a complication of long-term haemodialysis. Ann Rheum Dis 1986;45:1007-1011.

34. Bardin T, Zingraff J, Shirahama T, et al. Hemodialysis-associated amyloidosis and beta ${ }_{2}$-microglobulin. Clinical and immunohistochemical study. Am I Med 1987;83:419-424.

35. Nakazawa R, Hamagudnik, Hosaka E. Synovial amyloidosis of $\mathrm{B}_{2}$-microglobulin type in patients undergoing long-term hemodialysis. Nephron 1987;44:379-380.

36. Brown EA, Arnold IR, Gower PE. Dialysis arthropathy: Complication of long-term treatment with hemodialysis. Br Med J J 1986;292:163-166.

37. Bardin T, Kuntz D. The arthropathy of chronic haemodialysis. Clin Exp Rheumatol 1987;5:379-386

38. Vincent C, Revillard JP, Galland M, Traeger J. Serum beta-2microglobulin in hemodialysed patients. Nophron 1978;21 $260-268$

39. Blumberg A, Burgi $W$. Behavior of beta-2 microglobulin in patients with chronic renal failure undergoing hemodialysis, hemodiafiltration and continuous ambulatory peritoneal dialysis (CAPD). Clin Nephrol 1987;27:245-249.

40. Gardner $\mathrm{H}$. Bone lesions in primary systemic amyloidosis. $\mathrm{Br}$ J Radiol 1961;34:778-783.

41. Grossman R, Hensley GT. Bone lesions in primary amyloidosis. Am J Roentgenol 1967;101:872-875

42. Sargent MA, Fleming SJ, Chattopadhyay C, Ackrill P, Sambrook P. Bone cysts and haemodialysis-related amyloidosis. Clinc Radiol 1989;40:277-281

43. Kleinman KJ, Coburn JW. Amyloid syndromes associated with hemodialysis. Kidney Int 1989;35:567-575.

44. Gielen JL, vanHolsbeeck MT, Hauglustaine D, et al. Growing bone cysts in long-term hemodialysis. Skeletal Radiol 1990; 19:43-49.

45. Sundaram M, Seelig R, Pohl D. Vertebral erosions in patients undergoing maintenance hemodialysis for chronic renal failure. Am J Roentgenol 1987;149:323-327.

46. Ross LV, Ross GR, Mesgarzadeh M, Edmonds PR, Bonakdarpour A. Hemodialysis-related amyloidomas of bone. Radiology 1991;178:263-265.

47. Grateau G, Zingraff J, Fauchet M, et al. Radionuclide exploration of dialysis amyloidosis: Preliminary experience. Am Kidney Dis 1988:11:231-237.
48. Hawkins PN, Lavender JP, Pepys MP. Evaluation of systemic amyloidosis by scintigraphy with I 123-labeled serum amyloid P component. N Engl J Med 1990;323:508-513.

49. Kuntz D, Naveau B, Bardin T, Drueke T, Treves R, Dryll A Destrurtive spondyloarthropathy in hemodialysed patients. Arthritis Rheum 1984;27:369-375.

50. Rafto SE, Dalinka MK, Schieber ML, Burk DL, Kricun ME Spondyluarthropathy of the cervical spine in long-term hemodialysis. Radiology 1988:166:201-204.

51. Simkin PA, Campbell PM, Larson EB. Gout in Heberden's nodes. Arthritis Rheum 1983;26:94-97.

52. Watt I, Middlemiss $H$. The radiology of gout. Clin Radiol $1975 ; 26: 27-36$

53. Resnick D. The radiographic manifestations of gouty arthritis Crit Rev Diagn Imaging 1977;9:265-335.

54. Martel $W$. The overhanging margin of bone: A roentgenologic manifestation of gout. Radiology 1968;91:755-756.

55. Resnick D, Broderick TW. Intraosseous calcifications in tophaceous gout. Am J Roentgenol 1981;137:1157-1161.

56. Simkin PA. The pathogenesis of podagra. Ann Intern Med 1977;86:230-233

57. Wilkins E, Dieppe P, Maddison P. Evison G. Osteoarthritis and articular chondrocalcinosis in the elderly. Ann Rheum Dis $1983 ; 42: 280-284$.

58. Resnick D, Niwayama G, Goergen TG, et al. Clinical, radiographic and pathological abnormalities in calcium pyrophosphate deposition disease (CPPD): pseudogout. Radiology 1977:122:1-15.

59. McCarty DJ, Kohn NN, Faires IS. The significance of calcium phosphate crystals in the synovial fluid of arthritic patients: The "pseudogout syndrome." Ann Intern Med 1962;56:711737 .

60. Martel W, Champion CK, Thompson GR, Carter TL. A roentgenologically distinctive arthropathy in some patients with the pseudogout syndrome. Am I Roentgenol 1970;109:587605 .

61. Martel W, McCarter DK, Solsky MA, Good AE, Hart WR Braunstein EM, Brady TM. Further observations on the arthropathy of calcium pyrophosphate crystal deposition disease. Radiology 1981;141:1-15.

62. Ellman $\mathrm{MH}$, Krieger MI, Brown N. Pseudogout mimicking synovial chondromatosis. J Bone Joint Surg (Am) 1975;57 A 863-865.

63. Schumacher HR. Hemochromatosis and arthritis. Arthritis Rheum 1964;7:41-50.

64. Zitnan D. Sitaj S. Natural course of articular chondrocalcinosis. Arthritis Rheum 1976;19:363-390

65. Korst JV van der, Geevards J, Driessens FCM. A hereditary type of idiopathic articular chondrocalcinosis. Survey of a pedigree. Am J Med 1974;56:307-314

66. Resnick D, Niwayama G. Carpal instability in rheumatoid arthritis and calcium pyrophosphate deposition disease. Pathogenesis and roentgen appearance. Ann Rheum Dis 1977;36: 311-318.

67. Hutton CW, Doherty M, Dieppe PA. Acute pseudogout of the temporomandibular joint: A report of three cases and review of the literature. Br J Rheumatol 1987;26:51-52.

68. Doherty M, Dieppe PA. Acute pseudogout: "crystal shedding" or acute crystallization? Arthritis Rheum 1981;24:954957

69. Pritzker KPH, Phillips H, Luk SC, Kovern IH, Kiss A, Houpt JB. Pseudotumor of the temporomandibular joint: Destructive calcium pyrophosphate dihydrate arthropathy. I Rheumatol 1976:3:70-81

70. Lambert RGW, Becker FJ, Pritzer KPH. Calcium pyrophos- 
phate deposition disorder (CPPD) of the right temporomandibular joint. Skeletal Radiol 1990;19:139-141.

71. Sissons HA, Steiner GC, Bonar F et al. Tumoral calcium pyrophosphate deposition disease. Skeletal Radiol 1989;18:7987.

72. Ling D, Murphy WA, Kyriakos M. Tophaceous pseudogout. Am Roentgenol 1982;138:162-165.

73. Leisen J. Calcium pyrophosphate dihydrate deposition disease: tumorous form. Am J Roentgenol 1982;138:962.

74. McCarty DJ, Gatter RA. Recurrent acute inflammation associated with focal apatite crystal deposition. Arthritis Rheum $1966 ; 9: 804-819$.

75. Dieppe PA, Watt I. Crystal deposition in osteoarthritis: An opportunistic event? Clin Rheum Dis 1985;11:367-392.

76. McCarty DJ, Halverson PB, Cavreva GF, Brewer BJ, Kozin F. "Milwaukee shoulder"-Association of microspheroids containing hydroxyapatite crystals, active collagenase, and nentral protease with rotator cuff defects. Arthritis Rheum 1981; 24:464-473.

77. Dieppe PA, Doherty M, MacFarlane DG, Huton CW, Bradfield JW, Watt, I. Apatite associated destructive arthritis. Br J Rheumatol 1984;23:84-91.
78. Doherty M, Holt M, MacMillian P, Watt I, Dieppe P. A reappraisal of "analgesic hip." Ann Rheum Dis 1986;45:272-276.

79. Halverson PB, McCarty DJ, Cheung HS, Ryan LM. Milwaukee shoulder syndrome: Eleven additional cases with involvement of the knees in seven (basic calcium phosphate deposition disease). Semin Arthritis Rheum 1984;14:36-44.

80. Ronnigen $H$. Langeland $N$. Indomethacin treatment in osteoarthritis of the hip juint. Acta Orthop Scand 1979;50:169174.

81. Paul H, Reginato AJ, Schumacher HR. Alizarin red S staining as a screening test to detect calcium compounds in synovial fluid. Arthritis Rheum 1983;26:191-200.

82. Crocker PR, Dieppe PA, Tyler G, Chapman SK, Willoughby DA. The identification of particulate matter in biological tissues and fluids. J Pathol 1977;121:37-40.

83. Menkes CJ, Simon F, Delrieu F, Forest M, Delbarre F. Destructive arthropathy in chondrocalcinosis articularis. Arthritis Rheum 1976;19:329-348.

84. McCarty DJ, Lehr JR, Halverson PB. Crystal populations in human synovial fluid. Arthritis Rheum 1983;26:1220-1224.

85. Dieppe PA, Alexander GJM, Jones HE et al. Pyrophophate arthrophy: a clinical and radiological study of 105 cases. Ann Rheum Dis 1982;41:371-376. 